\title{
LAPAROSCOPIC TRANSABDOMINAL PRE-PERITONEAL (TAPP) PROCEDURE FOR GROIN HERNIA. HOW TO DO IT FOR BETTER OUTCOMES
}

\author{
R. Moldovanu ${ }^{凶}$ \\ 1) Department of surgery, University of Medicine and Pharmacy "Gr.T. Popa" Iaşi, Romania \\ 2) Department of surgery and oncology, Les Bonnettes Hospital, Arras, France
}

\begin{abstract}
LAPAROSCOPIC TRANSABDOMINAL PRE-PERITONEAL PROCEDURE (TAPP) FOR GROIN HERNIA. HOW TO DO IT FOR BETTER OUTCOMES (Abstract): The laparoscopic approach for the groin hernia repair has several advantages: decreased immediate and late postoperative pain, less numbness in inguinal aria, less mesh infection and a rapid recovery. However the good outcomes are not granted, and there are some key points to be followed for better postoperative results. The aim of this video is to highlight these TAPP (TransAbdominal Pre-Peritoneal) related key points, from the operative indication, pre operative preparation and surgical procedure, until the post operative follow up.
\end{abstract}

KEY WORDS: LAPAROSCOPY; GROIN HERNIA; TRANSABDOMINAL PREPERITONEAL PROCEDURE (TAPP)

SHORT TITLE: TAPP - How to do it

HOW TO CITE: Moldovanu R. Laparoscopic transabdominal pre-peritoneal procedure (TAPP) for groin hernia. How to do it for better outcomes. Jurnalul de chirurgie (Iaşi). 2013; 9(2): 193-196. DOI: 10.7438/1584-9341-9-2-13.

Video

\section{BACKGROUND}

The laparoscopic approach for the groin hernia repair has several advantages: decreased immediate and late postoperative pain, less numbness in inguinal aria, less mesh infection and a rapid recovery [1]. However the good outcomes are not granted, and there are some key points to be followed for better postoperative results.

The aim of this video is to highlight these TAPP (TransAbdominal PrePeritoneal) related key points, from the operative indication, pre operative preparation and surgical procedure, until the post operative follow up.

\section{TAPP INDICATIONS:}

TAPP can be performed in any type of hernia, even in complicated (strangulated) hernia [2,3]. Relative contraindications are the large inguino-scrotal hernias and history of radical prostatectomy [2,3]. Different general comorbidites (e.g. heart failure, chronic respiratory disease) can contraindicate the general anesthesia and, as consequence, the TAPP $[2,3]$.

\section{PREOPERATIVE PREPARATION}

There is no particular preparation; however it has to be highlighted the importance of comorbidites evaluation and adequate skin preparation. In this way it is important to note the preoperative antiseptic shower, the hair removing using a barber clipper, use of alcoholic based solution for skin preparation and the bladder emptying just before the procedure (facilitate the dissection and avoid bladder injuries) [2-4]. 


\section{ANESTHESIA AND OPERATIVE ROOM SET-UP; INSTRUMENTS}

General anesthesia is mandatory. The patient is placed in supine position, in a $15^{\circ}$ Trendelenburg tilt with both arms in adduction along the body; the laparoscopic tower is placed to the feet of the patient as the display to be located on the hernia's site $[5,6]$. The surgeon operates from the opposite side of the hernia near the patient's shoulder, and the assistant stands opposite to the surgeon $[5,6]$.

Three trocars are used: one of $10 \mathrm{~mm}$ and two of $5 \mathrm{~mm}$. Common laparoscopic instruments (fenestrated graspers, scissors, hook, needle holder etc.) are necessary. The $30^{\circ}$ laparoscope is preferable [5].

\section{SURGICAL PROCEDURE:}

Usually the pneumoperitoneum is performed using a Veress needle [5]. The open technique is used in patients with previous abdominal surgery and/or umbilical hernia. The $5 \mathrm{~mm}$ trocars are inserted under laparoscopic view control, laterally from the epigastric vessels to improve the ergonomics and triangulation [5].

The procedure starts by a careful exploration of the abdomen identifying the superficial anatomical landmarks (urachus, umbilical folds, epigastric vessels, spermatic vessels, vas deferens or uterine round ligament) and the site and type of hernia [7].

Then a large opening of the peritoneum is performed, from the anterosuperior iliac spine until the lateral umbilical ligament (umbilical artery cord) 2 to $3 \mathrm{~cm}$ beyond the parietal defect [1,3-6,8].

The dissection starts in Retzius space, in contact with abdominal rectus muscles, from laterally to medial and from cranial to caudal, "targeting" the pubic bone, dividing the fine conjunctive fibers ("angel hair") $[1,5]$. Then, the dissection is conducted from medial to lateral into the Bogros space, from epigastric vessels to spermatic vessels [5]. In the same time we start the dissection of hernia sac. The hernia sac is completely dissected using traction contra-traction maneuvers, sharp and blunt dissection and fine coagulation; it is mandatory to find the avascular plan to preserve the spermatic fascia and to protect the fragile parietal structures (vas deferens, vessels and nerves) $[1,5,8]$. The dissection has to be conducted in obturator fossa to identify the occult obturator hernias (type I obturator hernia) [5]. The dissection is completed when all the deep anatomic landmarks (Cooper, Gimbernat ligaments, corona mortis and external iliac vein) are well exposed and the pre peritoneal space is wide opened (at least $12 \times 15 \mathrm{~cm}$ ) to allow the correct mesh deployment and parietalization $[1,5,8]$.

It is important to search, dissect and remove the cord or pre peritoneal lipoma, because the overlooked lipomas could be misdiagnosed as recurrent hernia or seroma [9].

Afterwards, a large $(12 \times 15 \mathrm{~cm})$ light weight mesh is deployed in pre peritoneal space, positioning to cover all the parietal defects and fixed in appropriate position using absorbable staples [1-3,6,8]. For the bilateral hernia two overlapping mesh are used, stapled together on the midline [1-3,6,8].

In case of large hernia or after difficult dissection or in patients with risk of hemorrhage a suction drain is inserted in Retzius space [10]; it will be removed after 12 to 24 hours postoperatively.

The peritoneum is then carefully closed using continuous non absorbable suture secured with an extracorporeal knot; the closure using staples or barbed sutures is also possible [5]. The closure has to be "waterproof" to avoid small bowel herniation $[2,3]$.

The trocars are then removed under laparoscopic control view. Usually the trocar sites are infiltrated using ropivacaine, under laparoscopic view [5]. The pneumoperitoneum is then exsufflated and the trocars wounds are closed [5].

\section{POSTOPERATIVE PERIOD}

The usual postoperative analgesic therapy consists in anti inflammatory non 
steroid drugs (Paracetamol and Ketoprofen). Usually the patients are discharged in the same day or in first postoperative day [5]. To further control the pain, all the patients received a prescription with Paracetamol 500 mg x 3/day and Ketoprofen 100 mg x 2/day for the first 7 days [5]. A routine thromboembolic disease prophylaxis with lightweight heparin therapy for 7 days for all the patients, is usually performed even the subject is controversy $[2,3,5]$.

\section{COMPLICATIONS}

Different postoperative complications are noted in the literature: seroma, hematoma, chronic pain, ischemic orchitis or testicular atrophy, infertility.

Seroma is the most frequent complication of TAPP repair [2,3]; in my experience, I noted a $6 \%$ rate, [11] close to the rate reported in literature $(5.7 \%)[2,3]$; furthermore I noted a decreasing rate of seroma after the use of suction drains.

Hematoma is less frequent in endoscopic hernia repair than in open repairs, with a rate of about $8 \%[2,3]$; in my experience, hematoma was noted in only $1.8 \%$ cases [11].

Chronic pain, defined as persistence of pain 3 months after the operation [12], is less frequent in endocopic techniques, and especially after TAPP, than in open hernia repair [2,3]; it was noted in $0.6 \%$ in a previous work [11].

Several other complications after TAPP were reported in the literature with an incidence rate of $1 \%$ or less: wound / mesh infection, urinary retention, bladder damage, mesh migration, bowel obstruction, ischemic orchitis / testicular atrophy $[2,3]$.

The recurrence rate varies between 0.4 to $4.8 \%[2,3,13]$; I noted a $0.6 \%$ rate of recurrence and open anterior approach (Lichtenstein repair) has performed [11].

\section{CONCLUSIONS}

TAPP is valuable procedure for the cure of groin hernia; is associated with low rate of postoperative morbidity and recurrence. Both superficial and deep anatomic landmarks are easily recognizable. The laparoscopic exploration allows the treatment of incarcerated / strangulated hernias and the intra operative diagnosis of occult hernias. The procedure is suitable for day surgery.

\section{CONFLICT OF INTERESTS}

None to declare

\section{REFERENCES}

1. Collaboration EH. Laparoscopic compared with open methods of groin hernia repair: systematic review of randomized controlled trials. Br J Surg. 2000; 87(7): 860-867.

2. Simons MP, Aufenacker T, Bay-Nielsen M, et al. European Hernia Society guidelines on the treatment of inguinal hernia in adult patients. Hernia. 2009; 13(4): 343-403.

3. Bittner R, Arregui ME, Bisgaard T, et al. Guidelines for laparoscopic (TAPP) and endoscopic (TEP) treatment of inguinal Hernia [International Endohernia Society (IEHS)] Surg Endosc. 2011; 25: 2773-2843.

4. Tanner J, Moncaster K, Woodings D. Preoperative hair removal: a systematic review. J Perioper Pract. 2007; 17: 118-121, 124-132.

5. Moldovanu R, Pavy G. Laparoscopic transabdominal pre-peritoneal (TAPP) for bilateral inguinal hernia. Jurnalul de chirurgie (Iaşi). 2010; 6(3): 373-382.

6. Leroy J. Transabdominal preperitoneal approach (TAPP). E-publication: WeBSurg.com, Mar 2001; 1(3). [available online at http://www.websurg.com /ref/doi-ot02en194.htm]

7. Târcoveanu E, Bradea C, Moldovanu R. Anatomia laparoscopică a regiunii inghinale. Jurnalul de chirurgie (Iaşi); 2006; 1(4): 436446.

8. Bittner R, Leibl BJ, Jager C, Kraft B, Ulrich M, Schwarz J. TAPP - Stuttgart technique and result of a large single center series. Journal of Minimally Access Surgery. 2006; 2(3): 155159.

9. Nasr AO, Tormey S, Walsh TN. Lipoma of the cord and round ligament: an overlooked diagnosis? Hernia. 2005; 9: 245-247.

10. Tamme C, Scheidbach H, Hampe C, Schneider C, Kockerling F. Totally extraperitoneal endoscopic inguinal hernia repair. Results of 5203 hernia repairs. Surg Endosc. 2003; 17: 192-195.

11. Moldovanu R, Pavy G. Transabdominal preperitoneal (TAPP) laparoscopic inguinal hernia operation - a learning curve analysis. Chirurgia. 2012; 107(Suppl 1): S373. 
12. Aasvang E, Kehlet H. Classification of chronic pain. Descriptions of chronic pain syndromes and definitions of pain terms. Prepared by the International Association for the Study of Pain, Subcommittee on Taxonomy. Pain. 1986; Suppl 3: S1-S226.
13. Bittner R, Schmedt CG, Schwarz J, Kraft K, Leibl BJ. Laparoscopic transperitoneal procedure for routine repair of groin hernia. Br J Surg. 2002; 89(8): 1062-1066. 